\title{
Maker Literacies and Maker Citizenship in the MakEY (Makerspaces in the Early Years) Project
}

\author{
Jackie Marsh ${ }^{1, *(1)}$, Hans Christian Arnseth ${ }^{2}$ and Kristiina Kumpulainen ${ }^{3}$ (D) \\ 1 School of Education, The University of Sheffield, 241 Glossop Road, Sheffield S10 2GW, UK \\ 2 Department of Education, University of Oslo, Problemveien 7, 0315 Oslo, Norway; h.c.arnseth@iped.uio.no \\ 3 Department of Education, University of Helsinki, Yliopistonkatu 4, 00100 Helsinki, Finland; \\ kristiina.kumpulainen@helsinki.fi \\ * Correspondence: j.a.marsh@sheffield.ac.uk
}

Received: 24 May 2018; Accepted: 17 August 2018; Published: 28 August 2018

\begin{abstract}
In this paper, the potential relationship between creative citizenship and what may be termed 'maker literacies' is examined in the light of emergent findings from an international project on the use of makerspaces in early childhood, "MakEY" (see http:/ / makeyproject.eu). The paper outlines the concept of creative citizenship and considers the notion of maker literacies before moving on to examine how maker literacies might be developed in early-years curricula in ways that foster civic engagement. Three vignettes are offered of makerspaces in early-years settings and a museum in Finland, Norway, and the UK. The activities outlined in the vignettes might be conceived of as 'maker citizenship', a concept which draws together understandings of making, digital literacies, and citizenship. The paper considers the implications of this analysis for future research and practice.
\end{abstract}

Keywords: makerspaces; citizenship; maker literacies; multimodal learning

\section{Introduction}

Citizenship is a concept that has been the subject of extensive reflection over recent decades from a variety of disciplinary perspectives. Nie, Jun, and Stehlik-Barry (1996) [1] argue that the two key traditional perspectives on citizenship, the emphasis on individual needs and rights (classic liberalism) versus the citizen as constructed in the public realm (civic republicanism), are connected in complex ways and that 'the interpretation and justification of what is in our interest and what we value, both individually and collectively, is therefore bounded by this connection' (Nie et al., 1996:5) [1]. This tension between the individual and the collective dimensions of citizenship education can be seen in the research related to the ways in which digital media might help to achieve citizenship goals, from an emphasis on the use of digital tools (such as participatory video production) to support collective agency (e.g., Gomaa, 2004) [2], to a more neoliberal emphasis on the development of a set of digital competences that can enable individuals to become more effective citizens, as in some models of digital citizenship (e.g., Ribble, 2004) [3]. The dichotomy embedded within these approaches is an important one to explore, but the context for much of the related discussion in contemporary scholarship is invariably one that focuses on the digital literacy practices of older children and young people; the specific concerns of early childhood educators in this area are rarely addressed in the literature. This is, we would suggest, partly because the education of young children in 'Western' countries has traditionally been associated with the need to foster individual development rather than collective action (Kagitcibasi, 1996) [4], and there has also historically been an emphasis on children as 'becomings', rather than 'beings' who are also 'becomings' (Uprichard, 2008) [5]. As Stephen and Gadda (2017) [6] suggest, following a review of research related to citizenship in the early years, 'children have often been excluded from debates about citizenship due to their perceived lack of capacity' (p. 5). 
This is not the case in all countries. In Finland, the national early childhood education curriculum (for 0 to 5 years old) and preprimary education curriculum (for 6 years old) list 'Participation and involvement' as one transversal competence area that needs to be promoted in Early Childhood Education (ECE). This entails respecting children's rights and voice in matters that affect their lives. It also entails supporting children in participating and making an impact on collective decision-making on societally relevant matters. These activities are considered important in order to support young children's emergent citizen skills for democratic and sustainable futures (Finnish National Board of Education, 2016) [7]. However, the work of Stephen and Gadda (2017) [6] indicates that this is an exception, and that most ECE curricula do not make these matters explicit.

The challenge of promoting a more politically engaged curriculum in ECE, in which children are actively involved in considering some of the key issues that their communities face on a local level, is one that can be addressed by focusing on an approach to a digital literacies curriculum which fosters 'creative citizenship' (Hargreaves and Hartley, 2016) [8]. In this paper, the potential relationship between creative citizenship and what may be termed 'maker literacies' is examined in the light of emergent findings from an international project on the use of makerspaces in early childhood. The concept of maker literacies is one that has, arguably, emerged from the multiliteracies (New London Group, 1996) [9] framework, drawing together as it does the tropes of multimodal meaning making, design, and new technologies. In the first part of the paper, the key concepts are considered, including creative citizenship and the notion of maker literacies, before we move on to discuss how maker literacies might be developed in ECE curricula in ways that foster the three key elements of citizenship: belonging, participation, and rights (Bellamy, 2008) [10]. This, we argue, might be conceived of as 'maker citizenship', a concept which draws together understandings of making, digital literacies, and citizenship. This in turn relates to the notion of bildung as a broader goal for education that goes beyond neoliberal approaches.

\subsection{Creative Citizenship}

In recent years, there has been a challenge to traditional conceptualisations of citizenship which focus on an individual's relationship to a specific nation-state. Various scholars have outlined how normative models are exclusionary, and instead propose models of 'inclusive citizenship' (Lister, 2007) [11] and 'lived citizenship' (Warming and Fahnoe, 2017) [12], which align to localised, community political participatory practices. As Warming and Fahnoe (2017:4) [12] argue: 'By connecting the concept of citizenship with theories of radical democracy and inclusion, the lived citizenship approach aims to critically scrutinise the power relations that produce discrimination, domination, and exclusion'.

Lived citizenship therefore pertains to the everyday practices of people and enables a focus on issues relating to identities and communities rather than citizenship status. It also lends itself to studies of inclusion and exclusion, as those on the margins of society are frequently denied full rights and responsibilities and lived citizenship studies, instead, examine the life experiences that contribute to feelings of belonging or segregation (Lister, 2017) [11].

As part of their everyday practices, individuals engage in creative acts, some of which contribute directly to notions of lived citizenship. This has led to the development of the concept of 'creative citizenship' (Hargreaves and Hartley, 2016) [8], a term that has relevance to young children's engagement in makerspaces. In the UK, the concept of creative citizenship has been most recently pursued through a series of research projects funded by the Arts and Humanities Research Council through their Connected Communities funding call. Seeking to reclaim the concept of citizenship from social sciences, humanities scholars have focused on the way in which creativity through engagement in the arts can have a civic effect. This is the case even when, as Hargreaves maintains, the creative act 'does not have consciously civic intent' (Hargreaves, 2016:23) [8].

The use of creative acts for civic purposes may include such activities as flash mobbing (in which, for example, random crowds join together and undertake collective activities in public spaces) and 
yarn-bombing/guerrilla knitting (textile graffiti in public spaces). These are all examples of creative citizenship and 'critical making'. As Hughes (2016:143) [13] argues, rather than making for the sake of making, critical making is concerned with, 'the relationship between technologies and social life, with emphasis on their liberatory and emancipatory potential. Thus, it connects two practices that are often considered separate: critical thinking and creative expression (Ratto, 2011)' [14]. This can lead to what Ratto and Boler (2014) [15] term 'DIY Citizenship'.

This relationship between making and creative/DIY citizenship is one that is being pursued in the MakEY project (Makerspaces in the Early Years: Developing Digital Literacy and Creativity). This is a project which explores the place of the rising 'maker' culture in the development of children's digital literacy and creative design skills. In the next section, a brief overview of the maker movement is offered.

\subsection{Makerspaces and the Maker Movement}

There has been interest in recent years in the role of digital 'making', the design and production of digital artefacts, texts, and products in makerspaces (Blikstein, 2013 [16]; Johnson et al., 2015 [17]; Peppler, Halverson and Kafai, 2016) [18]. In our work, we have adopted the definition of makerspaces outlined by Sheridan Halverson, Litts, Brahms, Jacobs-Priebe, and Owens, (2014:507) [19], who suggest that 'Makerspaces are comprised of participants of different ages and levels of experience who work with varied media, but a commonality is that these spaces all involve making: developing an idea and constructing it into some physical or digital form'.

This is sufficiently broad to include everyday classroom makerspace provision as well as the more high-tech fabrication labs, or 'makerspaces', in which people use equipment, such as three-dimensional (3D) printers and laser cutters, for these purposes. A New Media Consortium (NMC) Horizon report suggests that such spaces have 'the potential to empower young people to become agents of change in their communities' (Johnson et al., 2015) [17].

A maker culture is one in which the process of creativity and innovation is key, and some have linked its genealogy to that of craftsmanship (Schrock, 2014) [20], although contemporary maker culture is focused less on the acquisition of a set of specific craft skills over a long period of apprenticeship, and is more concerned with a general approach in which anyone with access to the right tools and resources can create (Hatch, 2013) [21]. Makerspaces are part of the move to a 'DIY' culture in which citizens take the initiative and become more self-sufficient, made possible through the development of new digital tools and practices (Knobel and Lankshear, 2010) [22]. Rather than this being experienced as an individual process, however, makerspaces emphasise collaboration and sharing.

It has been argued that there are a variety of benefits to be accrued from participating in makerspaces. First, individuals develop a range of skills using a variety of tools as they hack and make. This may include the use of technologies. For example, Kafai, Searle, Fields, Lee, Kaplan, \& Lui (2014) [23] document that children creating wearable textiles, 'e-textiles', learned how computers and electronics work (p. 542). In relation to literacies, Santo $(2011 ; 2013)$ [24] contends that critical thinking is developed through participating in 'hacker literacies', which is described as a process of revising and being inventive with texts that are found in online sites, such as blogs. Engagement in hacking, tinkering, and making may, therefore, develop a range of '21st century' literacy skills (Jenkins et al., 2006) [25] that are crucial to future employment and leisure opportunities. A range of studies have considered the potential role that makerspaces have in education, identifying that they can foster a wide range of learning and lead to valuable educational opportunities (Halverson and Sheridan, 2004 [26]; Litts, 2015 [27]; Martin, 2015 [28]; Sheridan et al. (2014) [19]. There are recent studies that have considered the potential of makerspaces in schools for engaging pupils in 'making publics' (Stornaluolo and Philip, 2018) [29], that is, fostering civic action through making. This is an important area of work that can inform ECE practice, as outlined in this paper.

Peppler, Halverson, and Kafai (2016) [18] have pointed to the way in which much of the work on makerspaces to date has been focused on adolescents and adults and it is also clear that certain 
demographic groups have been privileged in these projects, such as affluent groups and males (Blikstein and Worsley, 2016; [18] Vossoughi, Hooper, and Escudé, 2016 [30]). Whilst a number of claims have been made about how makerspaces can promote democratic participation in society (Anderson, 2012) [31], the reality is rather different. The majority of makerspaces are located in urban spaces, which immediately excludes many people living in rural communities from participating. Further, Alper (2013:1) [32] reported on a U.S. survey that found that ' 8 in 10 makers are male, their median household income is $\$ 106,000$, and $80 \%$ have a post-graduate education', which indicates the need to ensure makerspaces reach out to all communities.

In the MakEY project, makerspaces are being created in a range of settings to which young children from a range of diverse communities have access, including early-years settings, schools, libraries, and museums. Emergent work on makerspaces in early-years settings and primary schools indicates that they have potential value for young children (Marsh, Kumpulainen, Nisha, Velicu, Blum-Ross, Hyatt, et al. (2017) [33], Shively, 2017 [34]; Tofel-Grehl, 2017 [35]). One of the aims is to explore how far children's engagement in makerspaces can develop 'maker literacies' in ECE, which is explored in the next section of the paper.

\subsection{Maker Literacies}

In considering the term 'maker literacies', attention needs to be paid to the problems posed by using 'literacy' as a metaphor, as Barton (2006) [36] has pointed out. 'Literacy' has been tacked on to all kinds of other terms as a marker of skills or competence, such as 'computer literacy' and 'information literacy'. Nevertheless, the term is deployed in this paper in order to convey the possibilities offered when literacy as semiotic meaning-making (making meaning as a social practice, drawing on a range of semiotic systems/multimodal resources: see Jewitt and Henrickson, 2016) [37] is used in ways that enable knowledge synthesis across disciplinary boundaries, facilitate learning about materials, and lead to the development of design skills. The term also can be argued to belong to a long tradition of ways of naming literacy that attend to its creative and design dimensions, including the concept of 'multiliteracies' (New London Group, 1996) [9].

Some scholars have adopted the term 'maker literacies' to refer to a very broad range of practices. Pawloski and Wall (2016:91) [38], in a book titled Maker Literacy, suggest that a 'Literacy Makerspace is an area set aside for children of all ages to tinker, create, and play while building skills from the multiple literacies: reading, science, art, math, art, technology, and so on'. For literacy scholars, this extension of the term into other subject areas is questionable, as it detracts from a consideration of what is particular about reading, writing, and multimodal/multimedia authoring within a makerspace context. In this sense, it might be of more value to consider maker literacies within the previously mentioned framework of 21st century literacies, in which multimodal text analysis, design, and production is at the heart of practice, practice which also fosters other skills, such as critical thinking, problem-solving, and communication. A number of models of 21st century literacies exist, each of them reflecting consistent elements of meaning-making, including: communication and creative innovation using a range of semiotic forms; the production and analysis of multimodal and multimedia/transmedia texts; the ability to engage in critical reflection and problem-solving, and the ability to network (see, for example, Burnett, 2016 [39]; Jenkins et al., 2009 [25]; NCTE, 2013 [40]).

It is clear that traditional conceptualisations of literacy are not sufficient in considering what happens in makerspaces, as they focus exclusively on meaning-making using lettered representation. Wohlwend and Peppler (2015) [41], in an analysis of their maker 'playshops', point to two ways in which literacy is expanded:

'First, playshops expand disciplines, such as literacy, to include printless storying, crafting, and other forms of design; this expands the scope of meaning-making practices beyond narrative storytelling in drama and literature disciplines to recognize emerging arts and design. Second, playshops expand paper/print tools to rapidly changing and increasingly intuitive technologies in 
fields such as digital media production, coding, and electronics in computer science and engineering.' (Wohlwend and Peppler, 2015:24) [41].

Wohlwend's work has led her to use the term 'maker literacies' to describe 'sets of practices for making and remaking artifacts and texts through playful tinkering with materials and technologies' (Wohlwend, Scott, Deliman and Kargin, 2018:148) [42]. This definition is useful, as it places semiotic meaning-making at the centre of the maker practice, unlike the use of the term by Pawloski and Wall (2016) [38]. Colvert (2015) [43], in her work on children's production of Alternate-Reality Games, also emphasizes the importance of social semiotics as a tool for thinking through multimodal making. Colvert maps the processes of multimodal text production and analysis onto Green's (1988) [44] 3D literacy model in order to identify what happens in the stages of text design, production, and reception.

Green (1988) [44] proposed that there were three elements of literacy: the operational (skills-based), cultural (understandings of literacy derived from cultural experiences), and critical (engaging critically with texts in terms of understanding issues of power, voice etc.). Colvert (2015) [43] argues that the processes of text analysis and production (design, production, interpretation, and design) can be mapped on to the 3D model in order to understand what is happening in any literacy event. This model was used to inform an understanding of digital literacy developed in the European Co-operation in Science and Technology [COST] Action DigiLitEY (Sefton-Green, Marsh, Erstad and Flewitt, 2016) [45], and it also can be usefully applied to a consideration of maker literacies, in which children design, produce, interpret, and disseminate a range of texts and artefacts that are created using a very wide range of both digital and non-digital tools and resources (see Table 1).

Table 1 is not intended to offer an exhaustive model of maker literacies; rather, it outlines some of the skills and understanding that can be employed/developed when engaged in text and artefact production and dissemination in makerspaces. In a practice-oriented approach to literacy, skills and understanding are inextricably linked to practices with materials. This may include the technical and fabrication knowledge required to manage and operate tools within the makerspace, such as $3 \mathrm{D}$ printers and laser cutters (captured within the 'operational' dimension). Table 1 does also not suggest that the products of design and production are all-important. In makerspaces, the process is significant (Peppler, Halverson and Kafai, 2016) [18]. Hacking, tinkering, and making may not lead to the production of a finished text or artefact, but, nevertheless, aspects of the process may be analysed using the grid below. Finally, underpinning all of the dimensions and practices identified in Table 1 are the important concepts of play and creativity. Makerspaces can foster play and creativity in early childhood settings, as the work of Wohlwend and Peppler (2015) [41] has demonstrated.

Whilst Table 1 outlines the kinds of processes, skills, and knowledge involved in multimodal meaning-making in makerspaces, it does not pay attention to other subject knowledge that might be developed in these spaces. As children create, for example, models that embody circuits, or use a laser cutter to create a template for a 3D design, they also develop knowledge in the realms of science and engineering. Maker literacy practices facilitate interdisciplinary learning through these kinds of processes, and ensure that Science, Technology, Engineering and Mathematics (STEM) subjects are approached in ways that make them enjoyable and meaningful. Socio-scientific issues and social design experiments are relevant here; what is important is making science relevant to local concerns in communities. In such practices, children may engage in traditional reading and writing using alphabetic print, create multimodal/multimedia texts and artefacts, and learn key scientific principles. Fluid movements across these different areas, along with an iterative process of creation, means that pinning down exactly what has been learned in a particular makerspace event is a challenge. Table 1 offers a starting point for tracing what has been learned in relation to maker literacies; assessment of the acquisition of STEM knowledge needs approaches that draw on existing curricula practices in that area. 
Table 1. Maker Literacies ${ }^{1}$.

\begin{tabular}{|c|c|c|c|}
\hline & Operational Dimension & Cultural Dimension & Critical Dimension \\
\hline Design & $\begin{array}{l}\text { Use a variety of tools, modes, media, and } \\
\text { materials to design texts and artefacts } \\
\text { Re-design texts and artefacts }\end{array}$ & $\begin{array}{l}\text { Understand design principles within a specific } \\
\text { social and cultural context, bringing their own } \\
\text { experiences to bear on the task }\end{array}$ & $\begin{array}{l}\text { Reflect critically on design principles } \\
\text { Choose modes, media, and materials to use for } \\
\text { specific purposes (e.g., to entertain, } \\
\text { persuade, etc.) and for particular audiences }\end{array}$ \\
\hline Production & $\begin{array}{l}\text { Use a variety of tools, modes, media, } \\
\text { and materials to produce texts and artefacts } \\
\text { Re-use/re-purpose/re-mix texts and } \\
\text { artefacts effectively }\end{array}$ & $\begin{array}{l}\text { Draw on own social and cultural experiences in the } \\
\text { creation of texts and artefacts } \\
\text { Allow feelings and emotions to shape the } \\
\text { production experience }\end{array}$ & $\begin{array}{l}\text { Reflect critically on the process of production, } \\
\text { to ask questions such as (i) How do I want to } \\
\text { present myself and others in this text or } \\
\text { artefact? (ii) What messages do I } \\
\text { want to convey? }\end{array}$ \\
\hline Interpretation & $\begin{array}{l}\text { Access and understand modes/media/materials } \\
\text { used in the production of a text/artefact } \\
\text { Comprehend meaning, interpret through analysis, } \\
\text { reflection, synthesis } \\
\text { Relate text/artefact to own prior understanding } \\
\text { and experience } \\
\text { Move beyond a literal to deductive and } \\
\text { inferential reading }\end{array}$ & $\begin{array}{l}\text { Draw on own social and cultural experiences in the } \\
\text { analysis and interpretation of texts and artefacts } \\
\text { Participate with others in collective review } \\
\text { and interpretation } \\
\text { Understand texts and artefacts in relation to the } \\
\text { social, historical, and cultural contexts in which they } \\
\text { were produced }\end{array}$ & $\begin{array}{l}\text { Reflect critically on the text or artefact that is } \\
\text { being engaged with, to ask questions such as: } \\
\text { (i) Who produced this? (ii) What can be } \\
\text { discerned of the producer's intentions? } \\
\text { (iii) How has the producer positioned the } \\
\text { reader/viewer/user? (iv) How do issues of } \\
\text { power work in this context? }\end{array}$ \\
\hline Dissemination & $\begin{array}{l}\text { Able to use a variety of tools, modes, media, } \\
\text { and avenues to disseminate texts and artefacts }\end{array}$ & $\begin{array}{l}\text { Understand most effective means of disseminating } \\
\text { texts and artefacts within the social and } \\
\text { cultural context } \\
\text { Reach out effectively to diverse audiences to } \\
\text { communicate meanings }\end{array}$ & $\begin{array}{l}\text { Reflect critically on modes of dissemination, } \\
\text { to ensure most effective use of them }\end{array}$ \\
\hline
\end{tabular}

${ }^{1}$ From Marsh 2017: 78 [33] (adapted from Colvert, 2015 [43]). 
In the MakEY project, there are a number of ways in which maker literacies are to be used to engage young children in critical multimodal making as well as creative making. These activities may be conceived as 'maker citizenship', thus aligning the concept directly with the maker movement and its attendant considerations. Before discussing how these notions are aligned through an analysis of the data, an overview of the project and the research design are offered.

\section{The MakEY Project: Research Design}

The project involves a consortium located across Denmark, Finland, Germany, Iceland, Norway, Romania, the UK, and the USA, consisting of academics, early-years practitioners, museum educators, librarians, makerspace staff, and artists. Each of these partners offers specific expertise to the project, based on their professional experience, and the projects involved them collaborating together to provide makerspaces for young children, and sometimes their families, which led to the co-construction of knowledge across these sectors. The main aim of the project is to, collaboratively across disciplines and sectors, examine the potential that makerspaces have in the early years in terms of fostering young children's digital literacy and creativity. Research questions are focused on examining the challenges and opportunities makerspaces offer at personal, relational, and institutional levels, whilst recognizing that these are all intertwined (for a full list of research questions, see: http://makeyproject.eu/about/).

In each of the countries involved, projects are being undertaken in which makerspaces are offered in a range of formal and non-formal settings, such as nurseries, schools, community spaces, museums, and libraries. These makerspaces involve children aged 3-8 and, in some cases, their parents. The workshops focus on different activities in the varied contexts. For example, workshops in Denmark emphasize playful uses of LEGO and digital electronics, workshops in Germany involve using Virtual Reality technology to create playworlds for dolls, workshops in Iceland involve arts, music-making, and programming, in Romania the emphasis is on robotics, and in San Francisco, CA, USA, family maker activities in three museums are being undertaken. All workshops delivered have been observed by each country team (i.e., researchers recording observations of the workshops through field notes and/or photography and/or video data where permissions could be gained) to enable comparisons to be undertaken across the countries (with at least five workshops observed by each country team), and a number of practitioners in the workshops have been interviewed. The numbers and types of practitioners interviewed have differed across countries. In some of the locations, in addition to researchers recording observations through field notes and camcorders, children are also engaged in data collection through the use of GoPro Cameras, which they opt to wear during makerspace workshops. Data analysis is being undertaken across the case studies using a shared set of predetermined codes (numbering 125), which have been developed in relation to the research questions (RQs). This paper addresses the RQ 'What kinds of digital literacy skills and creative competences do children develop through their participation in the makerspace?', and two key themes emerged from the analysis of data in the makerspaces focused upon in this paper. The first was that the practices the children engaged in could be identified as maker literacies, as described in Table 1 , and the second theme that emerged was that these makerspaces fostered maker citizenship, which may be defined as maker practices related to one or more of the three key elements of citizenship: rights, belonging, and/or participation. These themes are considered in the next section.

Ethical considerations have been paramount at all stages of the project, with informed consent being gained from parents, and with children being asked if they wish to participate both before and during the studies.

This paper reports on data from three of the countries involved in the project: Finland, Norway, and the UK. The Finnish case study involved nine six-year-old children and their two teachers. In the Norwegian study, one kindergarten teacher and one museum educator were interviewed individually, and a focus group interview with museum staff was undertaken. Eighteen children aged 5 and 6 participated in the workshops. In the UK study, observations were undertaken in a nursery with 45 3- and 4-year-old children. Two of their teachers and a local maker who participated in the case study 
were interviewed. Children also wore Go-Pro cameras during their time in the makerspaces. The data were selected for discussion because they addressed the key foci of the analysis for this paper, that is, maker literacies and maker citizenship.

\section{Findings: Maker Literacies and Maker Citizenship}

In the following vignettes, we outline how critical maker literacies (the third dimension in Table 1) facilitated maker citizenship practices in Finland, Norway, and the UK. In the following discussion, we focus on three key aspects of maker citizenship. First, making affords both individual and collective agency, which can lead to a strong sense of social inclusion. Second, making requires constraints for creativity and the development of cultures of facilitation when addressing issues that are key to communities, such as sustainability. Finally, making enables the building of counter-narratives about a community through a place-based approach. Through engaging in these kinds of practices, children can develop an understanding of one or more of the three key areas of citizenship: rights, belonging, and/or participation. These ideas are developed further in the following vignettes.

\subsection{Maker Citizenship in Finland: Fostering Individual and Collective Agency}

\subsubsection{Context}

In Finland, three maker projects were undertaken as part of MakEY. These projects took place with children aged 3 to 8 years old in a municipality-run public ECE centre, a primary school, and a local city library. This paper reports on one of these projects that took place in and across a preprimary classroom in an ECE center and a local city library.

The maker project was aimed at enhancing the children's maker literacies and maker citizenship via the children's engagement in developing multimodal narratives on the Finnish forest through the construction of material artefacts and digital storying. This 3-month long maker project was framed by the Whisper of the Spirit literature (Erfving, Hintsa, Sintonen, Sairanen, and Kumpulainen, 2017) [46] based on Finnish stories, myths, and ancient beliefs around nature. The Whisper of the Spirit literature encourages children to wonder, make sense, observe, experiment, reflect, imagine, and create in multimodal ways. These activities are considered important in enhancing children's developing multiliteracies (Kumpulainen, in press) [47] entangled with their place-responsive experiences through multimodal meaning-making and storying (Renshaw and Tooth, 2018) [48].

\subsubsection{The Project}

The project began by joint reading and multimodal meaning-making of the Whisper of the Spirit literature, including its illustrations. Figure 1 takes children to the Middle ages in Finland, when totem poles were made of animals to protect the nature and its people (Erfving, et al., 2017) [46]. An important part of the multimodal meaning-making was linking the literature into children's own experiences, reflections, and storying around forests.

In the joint discussions, attention was also directed to inviting the children to consider what they would like to 'make' for the forest. As the following account of the preprimary school teacher Corinne makes visible, the idea of the actual maker project discussed in this paper came from the children themselves.

Corinne: "We started the project with the children, with looking at totem poles via iPad, and discussing what else we have here in Finland. We talked about the Finnish sauna elf and home elf. From there, the idea of the spirits of the forest came. The ideas have come from the children. The children also chose what materials they wanted to use and collected them from the woods. They had clear visions from the beginning on how to make the spirits". 




Figure 1. Example from the Whisper of the Spirit literature.

Next, the children together with their teachers made a trip to the forest and collected materials from nature for their spirits. The children also went to see a play on forests. The teachers made sure that the visits included reflective discussions, critical analysis, and joint meaning-making. The maker project continued back in the ECE centre, the children designing and making their spirits for the forest. Figure 2 illustrates Bea designing, sketching, and making her spirit, namely the 'Spirit of the Trees'.


Figure 2. Bea designing, sketching, and making her 'Spirit of the Trees'.

The maker project proceeded by the children storying their spirits by recording their narrations and saving these digital stories linked to a Qick Response $\{Q R\}$ code for wider dissemination.

The following accounts from two children, Anna and Bea, illustrate the children's motives and sense making of their maker activities.

Anna: "My spirit protects the birds."

"We made spirits that protect something in the forest."

"I have planned and drawn my spirit, we will glue a bird on the spirit's shoulder, and it will have a dress with bird print. It protects birds and likes birds a lot. It will have a bird-necklace that I will make from thread." -Both girls make bird sounds. 
Bea: "My spirit protects plants, it is the spirit of plants. It protects the leaves and the trees and such... And pine trees..."

"The most fun was to make the spirit, it is sitting on a rock and the rock is so nice."

"I picked the materials from the forest, I have tree needles, and the rock, and such ... "

Adult: Why have you chosen to make spirits for these things, do you think they are important in some way?

Anna: They are really important in some way, they kind of protect the whole of nature.

Bea: Yes, you are not allowed to saw down trees, because the trees do not feel good about that. And you are also not allowed to take leaves from the trees.

After the children had finished their multimodal artefacts, these were taken into a local city library in which the children designed a public exhibition of their works supported by their teachers and librarians. Figures 3 and 4 illustrate the exhibition in the library. The visitors can view the material artefacts and listen to the children's digital stories linked to the QR codes.

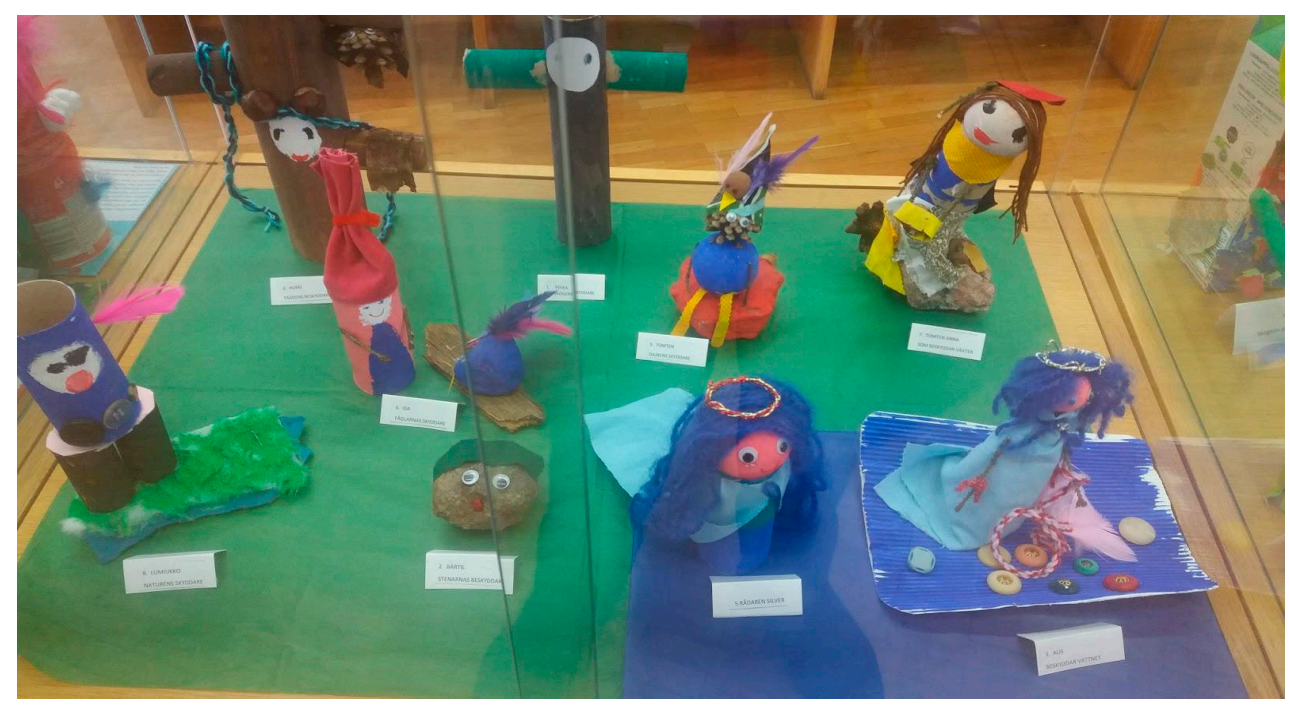

Figure 3. Spirits of the Forest exhibition.

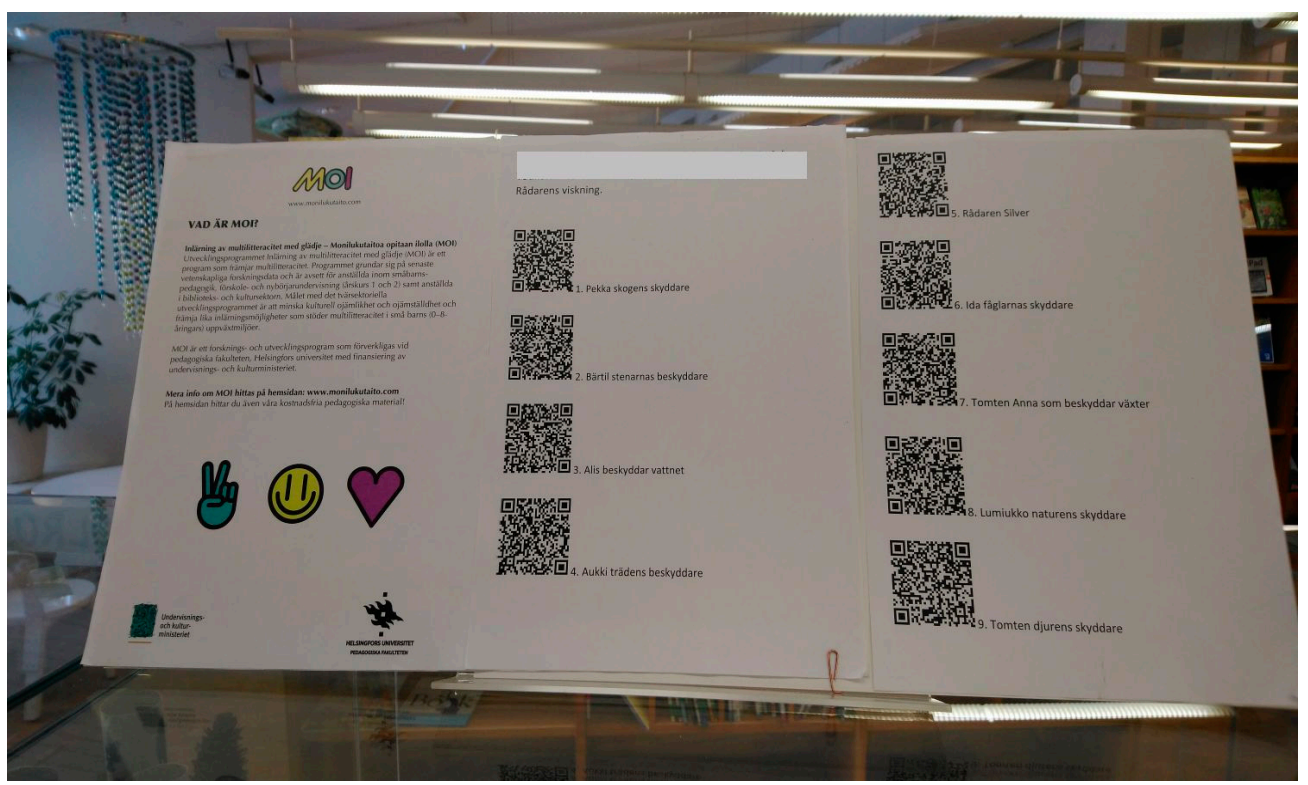

Figure 4. Digital stories of the Spirits of the Forest. 


\subsubsection{Individual and Collective Agency}

The preprimary school teachers experienced the maker project as having been empowering and emancipatory for the children and their families, as evidenced by the following account from one of the teachers:

"The best part with this project has been how active the children have been, and how this nature theme has been a part of our preprimary school activities for many months. The parents have also been active, sharing ideas and materials with us. The children have been very excited about this since the beginning, which made it so much fun for us as well".

In sum, the maker project in this Finnish preprimary classroom was designed to support the children's growth towards maker literacies and citizenship at the nexus of children's individual agency and collective agency for emancipatory, sustainable, and transformative futures (see also Nie et al., 1996 [1]; Gomaa, 2004 [2]). The maker project entailed the children being encultured into the Finnish stories, beliefs, and myths around forest, but at the same time also positioned the children as active producers of culture while they were invited to create their personal artefacts, i.e., Spirits for the forest, and stories on the forest. Furthermore, the maker project fostered collective agency by empowering the children to make their multimodal works and voices public via a joint exhibition in a local city library. This is likely to contribute to the ways in which the children think, view, and situate themselves in the world.

Drawing on the multiliteracies framework (New London Group, 1996) [9], the project wove together design, arts, multimodal meaning-making, and new technologies. The project went beyond the mere production of artefacts, creating opportunities for critical thinking and creative expression, thus expanding the children's activity from mere cultural enculturation to cultural production (Ratto, 2011 [14]; Hughes, 2016 [13]). The maker activities made children's unique voices visible in the form of multimodal art and digital production that led to a collectively designed exhibition in a local city library. These activities hold emancipatory and transformational potential at the level of the child and community.

The project makes visible maker literacies that entailed the children's critical and creative making and remaking of artifacts and texts through multimodal means and tools (Wohlwend, et al., 2018 [42]). All these literacies account for important elements of multimodal text design, production, and analysis, namely the operational, cultural, and critical as discussed previously (Colvert, 2015 [43]; Green, 1988 [44]). Not only did this maker project potentially enhance the children's maker literacies and maker citizenship, but it also transformed the status of the children from a typical position as a consumer of literature and library services into active agents and makers who contributed to the life of the library and its offerings to the community. The children's multimodal narratives on the forest also offer evidence of children's enhancing personal and collective appreciation of nature.

Altogether, the project makes visible how children's lived citizenship (Warming and Fahnoe, 2017 [12]) pertain to their everyday practices in ECE, enabling a focus on issues relating to their developing agency and identities as active community members and inclusive citizenship (Lister, 2007 [11]). The maker project demonstrates how the status of these children was transformed from mere socialisation towards active agency and creative citizenship. Here, the children's creative activities realised through their engagement in the design, arts, and multimodal meaning-making had a civic effect (see also Hargreaves, 2016) [8]. The project allows the team to examine how these multimodal and creative activities and experiences contribute to these children's agency, identity, and belonging, as well as to the development of their maker literacies and citizenship.

\subsection{Maker Citizenship in Norway: Constraints for Creativity and Cultures of Facilitation}

\subsubsection{Context}

In the Oslo, Norway element of MakEY, the research team worked closely with the National Science Museum in Oslo to develop activities where young children could engage in creative 
making and also become introduced to making in relation to issues of sustainable development. Through design-based research (DBR) they first observed activities in the museum where young children from kindergartens in Oslo engaged in an activity with Beebots. DBR is a systematic and flexible methodology for changing educational practices through iterative design and implementation, and at the same time studying those changes in systematic ways (Wang and Hannafin, 2005) [49]. The researchers in the project found this activity to be very structured and school-like, and wanted to explore whether it would be possible to design for activities that would be more creative and engaging and that would also, to a larger extent, include creative making with materials.

The museum had perfectly legitimate reasons for designing this as a school-like activity. Kindergartens and primary schools visit the museum for a limited time to undertake an activity which is educational and relevant to their curricula. Also, the activity structure makes it easier for museum educators to manage a diverse group of children. The museum educators were also very much aware of the dilemma between structure and freedom in designing activities for young children. Previously, they had also tried more open formats, but according to one of the museum educators it did not work very well: " . . because children became frustrated. They did not know what they should do ... so it faded out or they would cut straws without any goal. So when they got a mission, we saw that they collaborated better" (Interview with museum educator).

Keeping the notion of a mission or purpose, the research team wanted to explore further with the museum if they could design for more creative making. As input into this design activity, children were observed engaged in creative activities in the kindergarten, such as painting. In close dialogue with the museum educators the team discovered that they had an activity called "klimaverksted", which translates into something like 'a workshop to address climate change'. The research team and the museum agreed that this could be tweaked into an activity where the children could come up with ideas of what to make and reuse and how to reassemble materials and at the same time address important societal issues in their local communities and globally. This learning design clearly addresses issues of maker literacies and citizenship.

In the tweaking of the "klimaverksted", the team wanted to find ways of stimulating children's creative making without providing a very rigid format and structure to their work. They decided to use pictures where some were related to environmental issues and others that included pictures of machines, people, or other things that might make children start associating and come up with ideas for inventions they wanted to make.

Through engaging in creative activities where they built things together using recycled materials, the children were given the opportunity to reflect on and address issues of sustainable development. The children used paper cups, cardboard, wooden items, and other leftovers from other activities in the museum makerspace and built things from them using tape and glue.

The aim was not only to help children reflect critically on their own making, but also to situate their making within a broader societal context. Thus, the aim was to design for activities where children could learn to reflect on development and their role in development for the future, and develop their critical thinking around materials and the recycling of materials (see Figure 5).

\subsubsection{Constraints for Creativity and Cultures of Facilitation}

The notion of "constraints for creativity" has emerged as an important bridging concept through design-based research. This concept can incorporate several dimensions, such as open versus instructional learning designs and practices and transitive versus intransitive orientations (Jornet and Roth, 2018) [50]. 'Transitive' refers to how the practices are focused on making something, whereas 'intransitive' refers to the process of making in itself. What is called 'cultures of facilitation' is also crucial to how making happens and can be supported by educators. This also relates to where the locus of control in the activity is. For example, the team observed that when children ask for help and are in control of the making, their interest and engagement remains, while if the educators suggest or ask what children want to make at too early a stage, their engagement seem to fade more easily. 
However, conclusions concerning how activities should be supported by educators cannot be drawn from this. Whether to direct children's attention towards goals and products or to remain focused on the process is also dependent on where they are in their creative making and how much time they have available. In this context, introducing children to an overall mission and keeping an open rather than instructive facilitative approach seemed to support children's creative making. Further, it cannot be concluded that children from engaging in this small experiment developed any citizenship literacy. They were, however, introduced to activities where making was explicitly connected to citizenship issues. The early childhood educators also mentioned that creating such experiences for young children also happened in the kindergarten. To learn about materials, they buried different kinds of organic, plastic, and metal objects and observed what happened a year after. Thus, engaging in this kind of creative making also makes it possible to connect various sites for children, and can enable them to take a more critical stance towards characteristics of their local communities. In relation to STEM issues, the children also developed a certain rudimentary understanding of issues of sustainable development and understood that this problem required creative solutions.

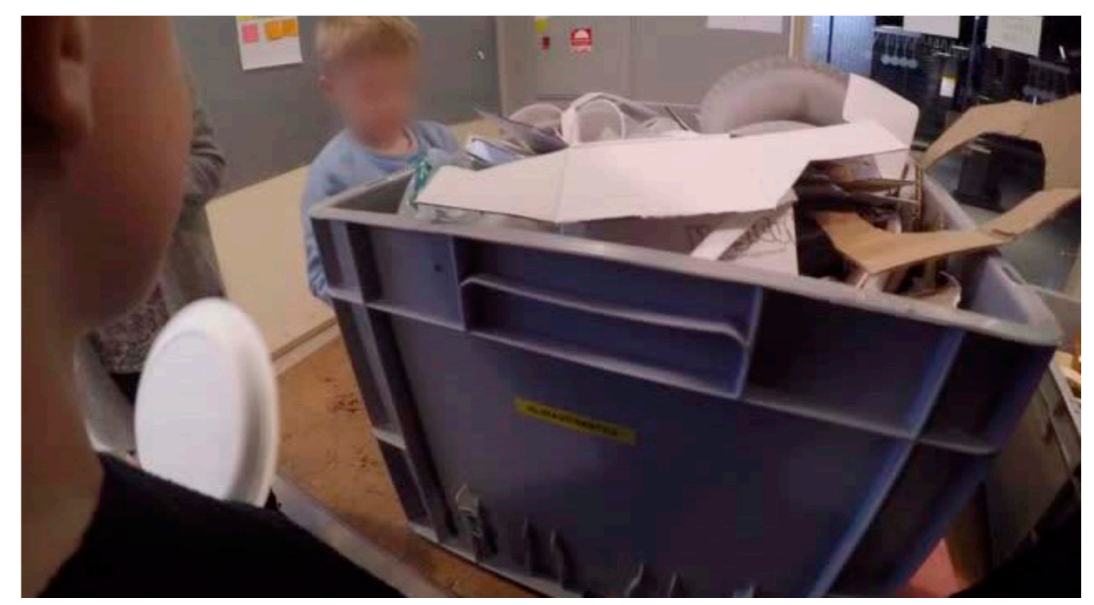

Figure 5. Children making things from recycled materials.

\subsection{Maker Citizenship in the UK: Building Counter-Narratives through a Place-Based Approach}

\subsubsection{Context}

In the Sheffield element of MakEY, projects in four different nurseries/schools were undertaken. This paper reports on one of these projects. The nursery concerned wanted the makerspace workshops to focus on the making of simple circuits, which was done through the children creating 3D models of their homes with their parents, that were then lit up using light-emitting diodes (LEDs) and batteries. The children also made street lights and lit-up Christmas trees to go alongside their homes. The street lights were created by using a template created by a local maker, James Wallbank (who set up the first open-access makerspace in Sheffield), that was then adapted by the children. The children created Christmas trees, supported by James, through the use of laser cuts of paper collages of trees they had made, which the children then lit up using copper tape, LEDs, and batteries. These models were then displayed in a room so that parents and others from the school could view them, and they were subject to tweets from teachers and governors (see Figure 6).

The children created virtual representations of their streets and trees through the use of iPad cameras, and these images formed the backdrop for green screen films in which children walked through forests of their Christmas trees, singing Christmas songs (see Figure 7). These multimodal, creative practices developed skills and knowledge across the model of maker literacies outlined in Table 1, and successfully integrated STEM with art, literacy, and music. 
It was amazing to see all the hard work of our nursery pupils today. I was super impressed by all the houses and Christmas trees. Well done

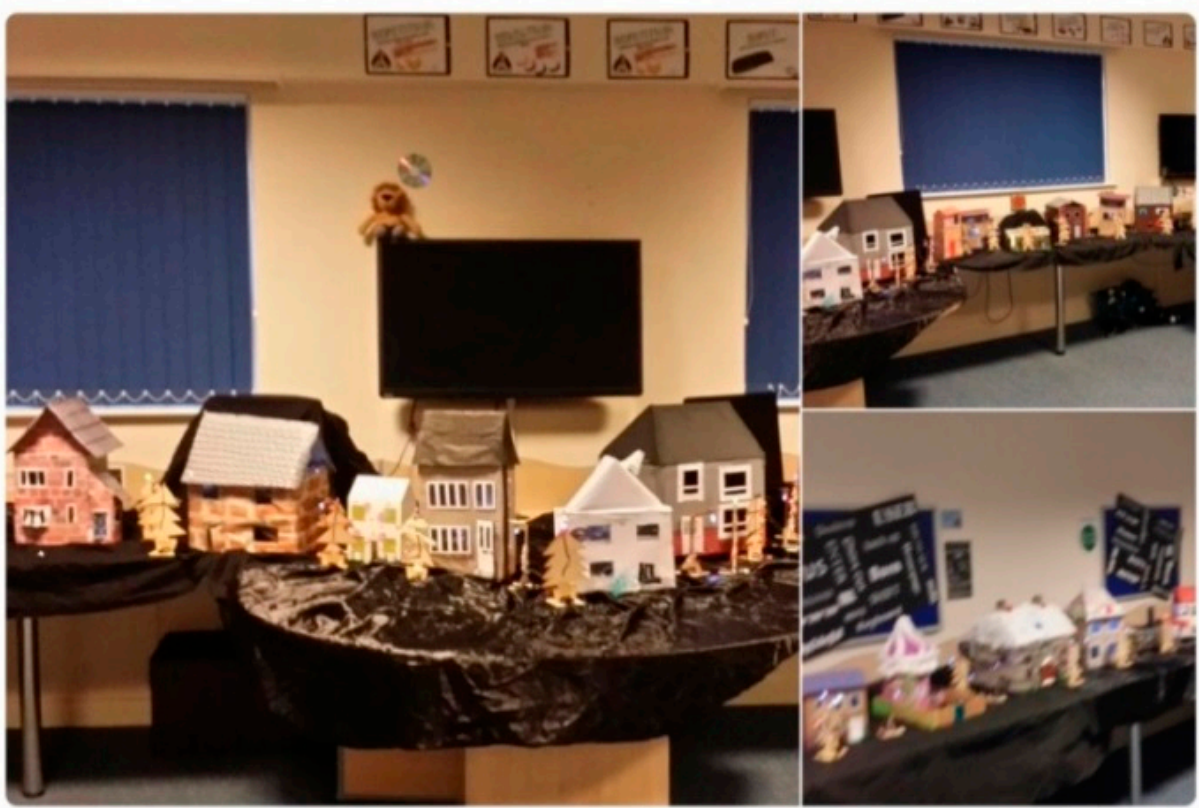
Q
†】 2
O 15

Figure 6. A tweet from a school governor about the exhibition.



Figure 7. Still from a film using green screen, in which children walked through their Christmas tree forest, singing Christmas songs. 


\subsubsection{Place-Based Maker Citizenship}

Throughout the work, discussions were undertaken with the children about what they liked and valued about their local community, and what they would want to add to it. For example, the following field notes were made by a researcher when observing a group of girls reflect on what else they would like in their vicinity:

'Six girls squashed together around a small table, which contained playdoh, LEDs, and batteries (As in the 'Squishy Circuits' model: https:/ / squishycircuits.com, see Figure 8). This was typical of this project: children were very keen to participate in all aspects of it, and chose freely when to engage, which sometimes meant that the demand was greater than the space available. There was no sense that girls were resistant to the STEM elements of this work. I had asked the children to discuss and make things that they would like to see in their neighbourhood in order to improve it, expecting the group to focus on play spaces and equipment but, instead, they decided they wanted more flowers around the estate, and Colleen, Stacy, Gabrielle, and Vicky got busy making them, using the electronics equipment to make the flowers light up. As they made the flowers, they discussed the colours they had used, and made references to their lovely smells. Sarah decided she preferred to make pancakes, although it was not clear if this related to the challenge set, and Vicky began to copy her, whilst Rhiannon watched them all, without making her own model. The girls were very interested in each other's creations, commenting as they were underway. As they worked on their models, I helped them when necessary with connecting the LEDs and batteries, and talked to them about what they liked about the estate, which included reference to people, dogs, and gardens.' (Fieldnotes, December 2017).

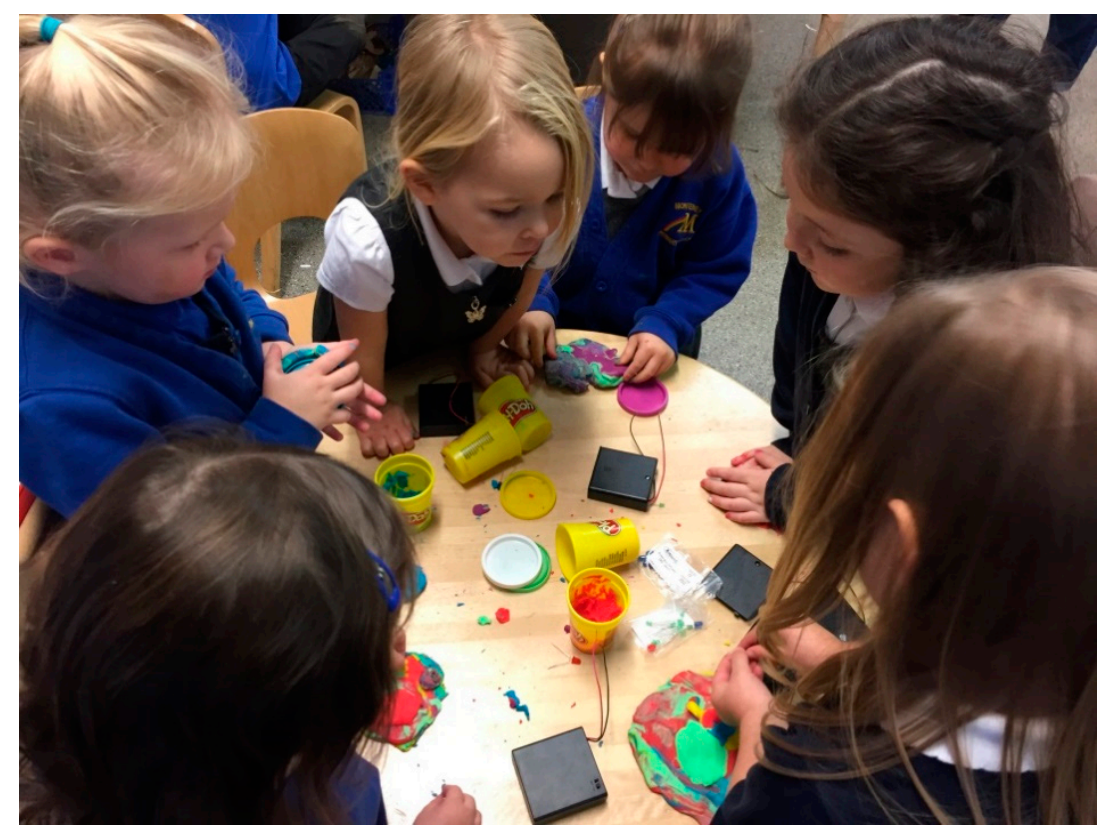

Figure 8. Girls making models of lit-up flowers to enhance their neighbourhood.

This activity was important in building a counter-narrative to media reports about the local area, which consistently label it as one of the most anti-social estates in the country and point to its high crime rates. The estate where the school is located is in the top $2 \%$ of deprived communities in England according to government statistics (Indicators of Multiple Deprivation [51], and faces the usual challenges that deprived communities encounter. As Devereaux, Haynes, and Power (2011) [52] point out, however, the stigmatisation of neighbourhoods such as this one privilege accounts of its negative aspects rather than the positive, and this can impact on the life-chances of members of the community (Permentier, van Ham, and Bolt, 2009) [53]. It is, therefore, important to offer young 
children an opportunity to actively construct counter-narratives. Reflecting on what they like about their homes, streets, and local spaces contributed to this task.

As Barbara Comber's (2016) [54] work in Australia on literacies and place has demonstrated so powerfully, activities such as those outlined above offer 'pedagogies of possibility'. Warming and Fahnoe (2017:7-10) [12] emphasize the significance of a place-based approach to exploring issues relating to lived citizenship. Pointing to the embodied nature of citizenship, they argue that feelings of belonging, and identities, are inextricably bound up with place. Therefore, enabling 3- and 4-year-old children to engage in critical reflections on their environment through making may help them to consider place from a personal perspective, starting from their own lifeworlds, which is an important step in the development of feelings of inclusion and belonging. It is, of course, critical that the children have future opportunities to build on this work so that they can develop an active voice in decisions made about their community, and this project should be only the beginning of such a process. How far the concept of maker citizenship is one that is sustainable in early-years settings in the UK, however, which are subject to policies that focus more on the datafication of childhood than emancipation (Roberts-Holmes, 2015) [55], is a focus for ongoing research in the Sheffield MakEY project.

\section{Conclusions}

These three vignettes each offer different perspectives on maker culture, maker literacies, and creative citizenship, and we have drawn on them to illustrate the concept of 'maker citizenship' in which young children's multimodal and multimedia meaning-making can be framed in ways which focus on one or more key aspects of citizenship: rights, belonging, and/or participation. Enactivists have argued that 'sensory and motor processes, perception, and action are fundamentally inseparable in lived cognition' (Thompson, 2007:173) [56], and therefore what the makerspaces outlined in this paper provided is an opportunity for children to explore their thoughts and feelings about their locality through embodied practices over time, practices that constitute, we would argue, maker citizenship. Whilst the possibilities are many in relation to this approach, the usual caveats apply. There has been a range of research that has pointed to the way in which it cannot be assumed that there is a direct connection between the digital production of children and youth and their enhanced agency, and the field has a number of gaps and silences which, Dussel and Dahya (2017:2) [57] suggest, include 'the role of media genres and technologies, the constraints of educational settings and authorities, the explicit or implicit dialogue with political and economic changes and public agendas, among other issues'. In considering young children's maker citizenship, it will be important to address these gaps and silences in order to avoid being overly celebratory about the possibilities for voice and agency in these practices.

Further, as research in this area develops in future years, there is a need to consider the support that early-years educators might need in order to successfully foster maker citizenship education in the classroom. This will not only require enhanced subject knowledge with regard to maker literacies, but also an understanding of the hyperlocal issues that would benefit from consideration by young children. A sensitivity to hyperlocal issues is part of the everyday lived experiences of many early-years practitioners, as they exchange news with parents and carers about these issues or respond to requests from community organisations and partners to become engaged in relevant campaigns. It is not the case that all of these issues would be of interest to very young children, nor is it the case that all hyperlocal challenges can be even partly addressed by their engagement. How early-years practitioners might make choices about when and where children may be engaged with the local political agendas is an issue that requires further research.

In addition, future research might also explore in further depth what it is about a maker culture that might enhance children's critical literacy skills and lead to direct action. Engaging young children in campaigning issues is not new, as the work of Vasquez (2004) [58] has demonstrated. She offered an account of how children in a U.S. kindergarten campaigned to ensure that vegetarian options were offered at a school fund-raising barbecue by writing letters and making posters. What is new are the 
forms of production, in that maker citizenship practices can now enable children to create new kinds of multimodal/multimedia artefacts, such as gifs for Twitter feeds, 3D-printed objects, and virtual reality environments. These might have specific benefits in particular contexts, such as when children want to communicate online in real time with their communities. In addition, what digital maker culture offers contemporary approaches to the development of critical literacies in the early years is the opportunity to create artefacts that can be disseminated quickly and across great distances to external audiences, thus facilitating the creation of links between hyperlocal campaigns in different locations. Global partnerships can, accordingly, be developed around issues that are of significance to young children across the world using social media apps such as WhatsApp and Instagram. Thus, the opportunities for the fostering of maker citizenship in ECE in future years are numerous if some of the challenges outlined above can be adequately addressed.

Author Contributions: Conceptualization, J.M.; Methodology, J.M., H.C.A., K.K.; Validation; H.C.A., K.K., J.M.; Formal Analysis, H.C.A., K.K., J.M.; Investigation, H.C.A., K.K., J.M.; Data Curation, H.C.A., K.K., J.M.; Writing-Original Draft Preparation, J.M., H.C.A., K.K.; Writing-Review \& Editing, J.M., H.C.A., K.K.; Project Administration, J.M.; Funding Acquisition, J.M., H.C.A., K.K.

Funding: This research was funded by the European Commission Horizon 2020 Programme, Grant No: 734720.

Acknowledgments: The authors acknowledge the helpful comments made by reviewers in relation to this paper, which informed the final version.

Conflicts of Interest: The authors declare no conflict of interest.

\section{References}

1. Nie, N.; Junn, J.; Stehlik-Barry, K. Education and Democratic Ship in America; The University of Chicago Press: Chicago, IL, USA, 1996.

2. Gomaa, E.H. Video Production as a Tool to Reinforce Media Literacy and Citizenship in Egypt. In Global Citizenship in a Digital World; Culver, S.H., Kerr, P.A., Eds.; Nordicom: Goteburg, Sweden, 2014; Available online: https://milunesco.unaoc.org/wp-content/uploads/2015/03/global_citizenship_in_a_ digital_world.pdf (accessed on 10 June 2018).

3. Ribble, M. Digital citizenship: Addressing appropriate technology behavior. Learn. Lead. Technol. 2004, 32, 6-11.

4. Kagitcibasi, C. Family and Human Development across Cultures: A View from the Other Side; Erlbaum: London, UK, 1996.

5. Uprichard, E. Children as 'being and becomings': Children, childhood and temporality. Child. Soc. 2008, 22, 303-313. [CrossRef]

6. Stephen, C.; Gadda, A.M. Nurturing Citizenship in the Early Years; University of Stirling: Stirling, UK, 2017; Available online: http://www.gcph.co.uk/assets/0000/6278/Nurturing_Citizenship_in_the_Early_Years. pdf (accessed on 10 June 2018).

7. Finnish National Board of Education. Varhaiskasvatuksen Opetussuunnitelman Perusteet; Määräykset ja Ohjeet, 17; Opetushallitus: Helsinki, Finland, 2016.

8. Hargreaves, I.; Hartley, J. (Eds.) The Creative Citizen Unbound; Policy Press: Bristol, UK, 2016.

9. The New London Group. A pedagogy of multiliteracies: Designing social futures. Harv. Educ. Rev. 1996, 66, 60-92. [CrossRef]

10. Bellamy, R. Evaluating Union Citizenship: Belonging, rights and participation within the EU. Citizsh. Stud. 2008, 12, 597-611. [CrossRef]

11. Lister, R. Inclusive Citizenship: Realizing the Potential. Citizsh. Stud. 2007, 11, 49-61. [CrossRef]

12. Warming, H.; Fahnoe, K. Social work and lived citizenship. In Lived Citizenship on the Edge of Society: Rights, Belonging, Intimate Life and Spatiality; Warming, H., Fahnoe, K., Eds.; Springer: Cham, Switzerland, 2017.

13. Hughes, J. Digital making with "at risk" youth. In Proceedings of the ICICTE Proceedings, Rhodes, Greece, 7-9 July 2016.

14. Ratto, M. Critical making: Conceptual and material studies. Technol. Soc. Life Inf. Soc. Int. J. 2011, 27, $252-260$.

15. Ratto, M.; Boler, M. DIY Citizenship: Critical Making and Social Media; MIT Publications: Cambridge, MA, USA, 2014. 
16. Blikstein, P. Digital Fabrication and 'Making' in Education: The Democratization of Invention. In FabLab: Of Machines, Makers and Inventors; Walter-Herrmann, J., Büching, C., Eds.; Transcript Publishers: Biedlefeld, Germany, 2013; pp. 203-222.

17. Johnson, L.; Adams Becker, S.; Estrada, V.; Freeman, A. NMC Horizon Report: 2015 K-12 Edition; The New Media Consortium: Austin, TX, USA, 2015; Available online: http:/ / cdn.nmc.org/media/2015-nmc-horizonreport-k12-EN.pdf (accessed on 10 June 2018).

18. Peppler, K.; Halverson, E.; Kafai, Y. (Eds.) Makeology: Makerspaces as Learning Environments; Routledge: New York, NY, USA, 2016.

19. Sheridan, K.; Halverson, E.R.; Litts, B.; Brahms, L.; Jacobs-Priebe, L.; Owens, T. Learning in the Making: A Comparative Study of Three Makerspaces. Harv. Educ. Rev. 2014, 84, 505-531. [CrossRef]

20. Schrock, A. "Education in disguise": Culture of a hacker and maker space. InterActions UCLA J. Educ. Inf. Stud. 2014, 10, 1-25. Available online: http:/ / escholarship.org/uc/item/0js1n1qg (accessed on 10 June 2018).

21. Hatch, M. The Maker Movement Manifesto; McGraw-Hill: New York, NY, USA, 2013.

22. Knobel, M.; Lankshear, C. (Eds.) DIY Media: Creating, Sharing and Learning with New Technologies; Peter Lang: New York, NY, USA, 2010.

23. Kafai, Y.B.; Searle, K.A.; Fields, D.A.; Lee, E.; Kaplan, E.; Lui, D. A crafts-oriented approach to computing in high school: Introducing computational concepts, practices and perspectives with e-Textiles. ACM Trans. Comput. Educ. 2014, 14, 1-20. [CrossRef]

24. Santo, R. Hacker literacies: Synthesizing critical and participatory medialiteracy frameworks. Int. J. Learn. Media 2011, 3, 1-5. [CrossRef]

25. Jenkins, H.; Clinton, K.; Purushotma, R.; Robison, A.J.; Weigel, M. Confronting the Challenges of Participatory Culture: Media Education for the 21st Century; MIT Press: Cambridge, MA, USA, 2009.

26. Halverson, E.R.; Sheridan, K. The maker movement in education. Harv. Educ. Rev. 2014, 84, 495-504. [CrossRef]

27. Litts, B.K. Making Learning: Makerspaces as Learning Environments. Ph.D. Thesis, University of Wisconsin-Madison, Madison, WI, USA, 2015. Available online: http:/ / www.informalscience.org/sites / default/files/Litts_2015_Dissertation_Published.pdf (accessed on 14 June 2017).

28. Martin, L. The Promise of the Maker Movement for Education. J. Pre-Coll. Eng. Educ. Res. 2015, 5, 30-39. [CrossRef]

29. Stornailuolo, A.; Philip, N. Making Publics: Mobilizing Audiences in High School Makerspaces. Teach. Coll. Rec. 2018, 120, 1-38.

30. Vossoughi, S.; Hooper, P.K.; Escudé, M. Making through the Lens of Culture and Power: Toward Transformative Visions for Educational Equity. Harv. Educ. Rev. 2016, 86, 206-232. [CrossRef]

31. Anderson, C. Makers. The New Industrial Revolution; Crown Publishing Group: New York, NY, USA, 2012.

32. Alper, M. Making Space in the Makerspace: Building a Mixed-Ability Maker Culture. In Proceedings of the Interaction Design and Children (IDC-13), New York, NY, USA, 24-27 June 2013; Available online: https: / / pdfs.semanticscholar.org/8d8a/ef7ff1f842a65e4fcbec9fb7d10deb46711a.pdf (accessed on 10 June 2018).

33. Marsh, J.; Kumpulainen, K.; Nisha, B.; Velicu, A.; Blum-Ross, A.; Hyatt, D.; Jónsdóttir, S.R.; Levy, R.; Little, S.; Marusteru, G.; et al. (Eds.) Makerspaces in the Early Years: A Literature Review; MakEY Project; University of Sheffield: Sheffield, UK, 2017; pp. 75-79. Available online: http:/ / makeyproject.eu/wp-content/uploads / 2017/02/Makey_Literature_Review.pdf (accessed on 10 June 2018).

34. Shiveley, K.L. Reflections from the Field: Creating and Elementary Living Learning Makerspace. Learn. Communities Res. Pract. 2017, 5, 3.

35. Tofel-Grehl, C.; Fields, D.; Searle, K.; Maahs Fladung, C.; Feldon, D.; Gu, J.; Sun, C. Electrifying Engagement in Middle School Science Class: Improving Student Interest Through E-textiles. J. Sci. Educ. Technol. 2017, 26, 406-417. [CrossRef]

36. Barton, D. Literacy: An Introduction to the Ecology of Written Language, 2nd ed.; Wiley-Blackwell: Oxford, UK, 2006.

37. Jewitt, C.; Henriksen, B. Social semiotic multimodality. In Handbook of Language in Multimodal Contexts; Klug, N., Stockl, H., Eds.; De Gruyter: Berlin, Germany, 2016; pp. 145-164.

38. Pawloski, L.; Wall, C. Maker Literacy: A New Approach to Literacy Programming for Libraries; Libraries Limited: Santa Barbara, CA, USA, 2016. 
39. Burnett, C. A Framework for 21st Century literacies? Keynote address to COST Action IS1410. In Proceedings of the Digital Literacy and Multimodal Practices of Young Children, Third Meeting, Larnaca, Cyprus, 17-18 March 2016; Available online: http:/ / digilitey.eu/wp-content/uploads/2015/09/Cathy-Burnett-21stLiteracies.pdf (accessed on 10 June 2018).

40. National Council for the Teaching of English (NCTE). The NCTE Definition of 21st Century Literacies, 2013. Available online: http:/ / www.ncte.org/positions/statements/21stcentdefinition (accessed on 10 June 2018).

41. Wohlwend, K.E.; Peppler, K.A. All rigour and no play is no way to improve learning. Kappan 2015, 96, $22-26$. [CrossRef]

42. Wohlwend, K.E.; Scott, J.A.; Yi, J.H.; Deliman, A.; Kargin, T. Hacking Toys and Remixing Media: Integrating Maker Literacies into Early Childhood Teacher Education. In Digital Childhoods-Technologies in Children's Everyday Lives; Danby, S.J., Fleer, M., Davidson, C., Hatzigianni, M., Eds.; Springer: Berlin, Germany, 2018.

43. Colvert, A. Ludic Authorship: Reframing Literacies through Peer-to-Peer Alternate Reality Game Design in the Primary Classroom. Ph.D. Thesis, Institute of Education, University College of London, London, UK, 2015.

44. Green, B. Subject-specific literacy and school learning: A focus on writing. Aust. J. Educ. 1988, 32, $156-179$. [CrossRef]

45. Sefton-Green, J.; Marsh, J.; Erstad, O.; Flewitt, R. Establishing a Research Agenda for the Digital Literacy Practices of Young Children: A White Paper for COST Action IS1410. 2016. Available online: http:/ / digilitey. eu/wp-content/uploads/2015/09/DigiLitEYWP.pdf (accessed on 10 June 2018).

46. Erfving, E.; Hintsa, A.; Sintonen, S.; Sairanen, H.; Kumpulainen, K. Haltijan Kuiskaus; Helsinki University Library: Helsinki, Finland, 2017.

47. Kumpulainen, K. Promoting the joy of learning multiliteracies from early years onwards: An educational reform initiative in Finland. Media Educ. Res. J. 2018, in press.

48. Renshaw, P.; Tooth, R. Diverse Pedagogies of Place: Educating Students in and for Local and Global Environments; Routledge: London, UK, 2018.

49. Wang, F.; Hannafin, M.J. Design-based research and technology-enhanced learning environments. Educ. Technol. Res. Dev. 2005, 53, 5-23. [CrossRef]

50. Jornet, A.; Roth, W.-M. Imagining design: Transitive and intransitive dimensions. Des. Stud. 2018, 56, $28-53$. [CrossRef]

51. Official Statistics: English Indices of Deprivation 2015. Available online: https://www.gov.uk/government/ statistics/english-indices-of-deprivation-2015 (accessed on 10 June 2018).

52. Devereux, E.; Haynes, A.; Power, M.J. Tarring everyone with the same shorthand? Journalists, stigmatization and social exclusion. J. Theory Pract. Crit. 2011, 13, 500-517. [CrossRef]

53. Permentier, M.; van Ham, M.; Bolt, G. Neighbourhood reputation and the intention to leave the neighbourhood. Environ. Plan. A 2009, 41, 2162-2180. [CrossRef]

54. Comber, B. Literacy, Place and Pedagogies of Possibility; Routledge: New York, NY, USA, 2006.

55. Roberts-Homes, G. The 'datafication' of early years pedagogy: 'If the teaching is good, the data should be good and if there's bad teaching, there is bad data'. J. Educ. Policy 2015, 30, 302-315. [CrossRef]

56. Thompson, E. Mind in Life: Biology, Phenomonology and the Sciences of the Mind; Harvard University Press: Cambridge, MA, USA, 2007.

57. Dussel, I.; Dahya, N. Introduction: Problematizing voice and representation in youth media production. Learn. Media Technol. 2017, 42, 1-7. [CrossRef]

58. Vasquez, V. Negotiating Critical Literacies with Young Children; Routledge: Mahwah, NJ, USA, 2004.

(C) 2018 by the authors. Licensee MDPI, Basel, Switzerland. This article is an open access article distributed under the terms and conditions of the Creative Commons Attribution (CC BY) license (http://creativecommons.org/licenses/by/4.0/). 